\title{
Knowledge and causal attributions for mental disorders in HIV- positive children and adolescents: Results from rural and urban Uganda
}

W. Nalukenge ${ }^{\mathrm{a}^{*}}$, F. Martin ${ }^{\mathrm{b}}$, J. Seeley ${ }^{\mathrm{a}, \mathrm{c}}$, E. Kinyanda $\mathrm{a}^{\mathrm{a}, \mathrm{c}, \mathrm{d}}$

${ }^{a}$ MRC/UVRI Uganda Research Unit on AIDS, Entebbe Uganda Tel. +256 (0)

417704000; ${ }^{b}$ University of Bath, Department of Psychology, Claverton Down, Bath UK BA2 7AY; 'London School of Hygiene and Tropical Medicine, Keppel St, London WC1E 7HT, United Kingdom. Tel: +44 (0)20 7927 2482; ${ }^{d}$ Makerere University, Department of Psychiatry, P.O. Box 7072, Kampala, Uganda. Tel: +256-414530020.

*MRC/UVRI Uganda Research Unit on AIDS, P. O. Box 49, Entebbe Uganda Tel. +256 (0) 417704000 . Email: winfred.nalukenge@mrcuganda.org 


\section{Knowledge and causal attributions for mental disorders in HIV- positive children and adolescents: Results from rural and urban}

\section{Uganda}

Increasing availability of antiretroviral treatment (ART) has led HIV to be considered a chronic disease, shifting attention to focus on quality of life including mental wellbeing. We investigated knowledge and causal attributions for mental disorders in HIV-positive children and adolescents in rural and urban Uganda. This qualitative study was nested in an epidemiological mental health study among HIV-positive children and adolescents aged 5-17 years from five HIV clinics in rural and urban Uganda. In-depth interviews were conducted with caregivers of HIV-positive children (5-11 years) and adolescents (12-17 years) in HIV care. Data were collected on a brief life history of the caregivers and adolescents, and knowledge of mental disorders were explored using vignettes. Interviews were audio recorded with permission from participants before. Written consent and assent to participate in the study was sought before study procedures. A total number of 38 participants (19 caregivers and 19 children/adolescents) were interviewed. Age range of caregivers was 28-69 years; the majority were female (17). There was little knowledge on mental disorders among caregivers with only 3 able to relate the case study in the vignette to a mental problem. Factors attributed to mental disorders by caregivers were: improper upbringing, violence, poverty and bereavement. Five of the 19 adolescents identified vignettes as portraying mental disorders. Causes mentioned were: ill health of the parents, bereavement, child abuse, discrimination, HIV and poverty. Caregivers are not knowledgeable about behavioural and emotional challenges in HIVpositive children/adolescents. Mental health literacy programmes at HIV care clinics are essential to enhance treatment-seeking for mental health.

Keywords: caregivers; adolescents; HIV; mental disorders; mental health; psychiatric disorders. 


\section{Background}

Increasing access to antiretroviral therapy (ART) even in low income settings such as in Uganda means that many children born with HIV are now surviving to adulthood moving the focus from survival to quality of life, including mental wellbeing (Deeks, Lewin, \& Havlir, 2013; Laughton, Cornell, Boivin, \& Van Rie, 2013; Ministry of Health Uganda, 2013; Mutumba et al., 2016; Paramesparan et al., 2010). To address this, the World Health Organization (WHO) has recommended the integration of mental health into general HIV care (WHO, 2015), a call that has been taken up by many African governments including the Uganda government (Uganda AIDS Commission, 2015). Despite this, the majority of HIV care services on the continent still do not provide mental health services (Abas et al., 2017). Lack of demand for formal mental health services has been highlighted as one of the problems facing the development of mental health services in HIV care in Uganda (Wagner et al., 2014). Underlying this lack of demand for mental health services are alternative explanations for mental health problems by persons living with HIV (PLWH) and their caregivers which then influence health seeking behaviours. To explore this, we undertook a study among children and adolescents with HIV in care, and caregivers in central and southwestern Uganda.

\section{Methods}

\section{Study design and setting:}

This qualitative sub-study was nested within an epidemiological study entitled, 'Mental health among HIV infected $C H$ ildren and Adolescents in KAmpala and Masaka, Uganda' (the CHAKA study)' which was undertaken to investigate the pattern and 
burden of psychiatric disorders and how these impacted social and academic functioning (Mpango et al., 2017). Participants were recruited from four HIV care clinics in both urban Kampala and rural Masaka districts. For the qualitative sub-study, young people with HIV between 5-17 years of age who attended with a carer were randomly selected on first come basis to participate in the study. If the child was 5-11 years of age, the carer was interviewed. Adolescents (12-17 years) took part in interviews themselves. Informed consent was gained from the carer and assent from the adolescent.

\section{Data collection and analysis:}

After a carer or adolescent briefly described their life history, a vignette was read to them to explore their knowledge of mental disorders. The vignettes offered case examples of conduct disorder, depression, ADHD (Attention Deficit Hyperactive Disorder) or neurocognitive disorder, based on the Child and Adolescent Symptom Inventory-5 (CASI-5), a structured psychiatric diagnostic instrument based on the Diagnostic Structured Manual-5 (DSM-5) that was used in the epidemiological study (Gadow \& Sprafkin, 2013). Gender specific vignettes were constructed by a psychiatrist (Eugene Kinyanda) to each include at least three DSM-5 diagnostic items of the investigated disorder. After construction, these vignettes were then reviewed by a team consisting of two child psychologists, one from Norway (Birthe Knizek) and other from Uganda (Richard Mpango) for their validity and cultural appropriateness.

Data were collected from July to November in 2014 and interviews were conducted by an experienced qualitative researcher (Winifred Nalukenge). Interviews were from 30 to 45 minutes long. Respondents were given a vignette which closely 
matched the situation of the attending youth. Each participant was asked the question "what do you think is the problem in the vignette? Interviews were audio-recorded, transcribed verbatim and analysed thematically (Braun \& Clarke, 2006), managed by qualitative data software Nvivo-10. Each was reimbursed with transport equivalent to Uganda Shs. 10,000 (US\$3.3). No other incentive was given.

\section{Ethical approval:}

The study was approved by the Science and Ethics Committee of the Uganda Virus Research Institute, the Uganda National Council for Science and Technology and the Observational Research Ethics Committee of the London School of Hygiene and Tropical Medicine.

\section{Results}

\section{Participant characteristics}

Thirty-eight participants took part in the study, including 19 primary caregivers (2 male, 17 female)bringing in a child of 5-11years of age to the clinic and 19 adolescents ( 8 male, 11 female). The characteristics of the respondents are described in Table 1 below.

[Table 1 near here]

Briefly, thirteen of the adolescents were in primary school ( 7 female, 6 males) while two males had dropped out of school due to financial reasons. Thirteen were orphaned (7 male, 6 female) and living either with the mother (5), grandmother (5) or other relative (3). All adolescents in the study vertically acquired HIV and on ART since childhood. 
See table 2 below for summary of results on mental disorders in HIV-positive children and adolescents.

[Table 2 near here]

\section{Knowledge and recognition of mental disorders}

Caregiver's Views

Across the vignettes, caregivers commonly stated 'I don't know' or expressed uncertainty when ask what the problem was that a vignette illustrated. Of the 19 caregivers, only three clearly expressed that the vignette was about a mental or brain difficulty.

\section{Adolescents'views}

The adolescents expressed less uncertainty and more commonly identified the difficulties as mental health: 5 of the 19 adolescents related the vignettes to psychiatric problems. For example, for the conduct disorder vignette, although social challenges were identified as the general cause, some however related this to a mental health problem:

He has a mental disorder. It means a person's head is not functioning as normal. The brain is in disorder and the person does strange things like taking alcohol and fighting (14 year old male)

\section{Causal attributions of mental health problems}

Overall caregivers described the causes of mental health difficulties as poverty, violence, HIV-related disease, negligence, bereavement and effect of ART. Adolescents displayed a similar range of views, focusing on family illness, abuse and discrimination 
but also mentioning poverty and other social issues, in addition to bereavement and HIV.

Poverty and HIV associated negative life events:

Regarding depression, a 44 year old male, urban caregiver attributed it to poverty, HIV associated negative life events and side effects of ART as described below:

It's because of poverty and sickness of his parents who have no money to help him. If he does not eat and has to take drugs, then it is not easy for the young man to sustain life. The medicine is very strong and you cannot take that medicine like that young man there.

\section{Heavy workload and grief:}

A 16 year old female from the urban area attributed depression to a heavy workload and grief:

I think it's because of too much work coupled with the fact that she was refused to attend the burial of her father. Her heart is full of sorrow.

\section{HIV infection and low intelligence:}

HIV associated neurocognitive disorder was perceived by adolescents to be due to HIV infection and low intelligence. Contrastingly to the carer views, adolescents also associated this problem to non-adherence rather than medication side effects:

He may not be able to take his drugs well. He may play a lot and forget. I think he has little brains in that when they teach him something, he cannot grasp it. They can teach him because he was not taking his medicine well 
(16-year-old male).

\section{Sources of knowledge for mental illness}

Both caregivers and adolescents described their source of knowledge to have come from their experiences with family members who have suffered from these mental health problems. Adolescents additionally described their source of knowledge to also include their personal experience. For example, a 16 year old female felt that her personal experience was very similar to that described in the vignette:

I was just like [that]. Often times I think of how I didn't get a chance to see my father, I have three siblings, but I don't know where they are, mother is also dead. I was taken to my aunt who treated me so badly. She took me to work as housemaid at 6 years. She took all the money I earned...

\section{Discussion}

We have explored the knowledge and causal attributions for mental disorders in HIV-positive children and adolescents in rural and urban settings in Uganda. Our findings indicate different knowledge and attributions of mental health difficulties between caregivers and adolescents. Few caregivers related vignette descriptions to mental health difficulties in contrast to the adolescents where several of them were able to describe the vignettes as relating to mental health. This was probably because the majority of both the carers and adolescents used knowledge arising from their experiences in the community to explain these illnesses. Adolescents who were all HIVpositive tended to have more personal experiences of the described mental health problems. 
In the absence of formal knowledge, participants in this study could be seen actively creating knowledge from experience, a previously observed process (White, 1982; White \& Marsella, 1982). Knowledge of mental health built upon visible examples of people's distress in the community is one-dimensional. It is based only on what is publicly seen and discussed, and in our findings were derived from extreme examples of mental distress. It is important to address this knowledge gap or else there is a complex vicious cycle. Experiences seen in the community create a single, dominant, extreme narrative about mental health. Less extreme, common mental health problems are then not viewed as related to mental health, as such help seeking is then limited to more severe cases. When help is not sought, young people may have ongoing mental health problems in later life, increasing the burden of these difficulties on the individual, community and economy (Patel, Flisher, Hetrick, \& McGorry, 2007). Mental health related stigma may also lead to poor help seeking when symptoms are normalized in avoidance of being called mentally ill. Focus in care is sometimes put on symptoms and refer to children by their mental health symptoms and fail to recognize the multiple needs of the child (Heflinger \& Hinshaw, 2010).

\section{Limitation:}

Adolescents and caregivers in the study were from HIV care units in central Uganda. There are HIV-positive children and adolescents not in care whose opinions on mental disorders remain unknown. Further research in this area would lead to focussed interventions for all groups.

\section{Conclusion:}


It is necessary to address this absence of formal knowledge about HIV

associated mental health problems among both the adolescents and carers. This can be addressed by including mental health literacy in youth HIV care programming.

\section{References}

Abas, M., Nyamayaro, P., Bere, T., Saruchera, E., Mothobi, N., Simms, V., . . . Magidson, J. (2017). Feasibility and Acceptability of a Task-Shifted Intervention to Enhance Adherence to HIV Medication and Improve Depression in People Living with HIV in Zimbabwe, a Low Income Country in SubSaharan Africa. AIDS and Behavior, 1-16.

Braun, V., \& Clarke, V. (2006). Using thematic analysis in psychology. Qualitative research in psychology, 3(2), 77-101.

Deeks, S. G., Lewin, S. R., \& Havlir, D. V. (2013). The end of AIDS: HIV infection as a chronic disease. The Lancet, 382(9903), 1525-1533.

Heflinger, C. A., \& Hinshaw, S. P. (2010). Stigma in child and adolescent mental health services research: Understanding professional and institutional stigmatization of youth with mental health problems and their families. Administration and Policy in Mental Health and Mental Health Services Research, 37(1-2), 61-70.

Laughton, B., Cornell, M., Boivin, M., \& Van Rie, A. (2013). Neurodevelopment in perinatally HIV-infected children: a concern for adolescence. Journal of the International AIDS Society, 16(1).

Ministry of Health Uganda. (2013). Status of Anti-Retroviral Therapy Services in Uganda. . In K. S. A. C. Programme (Ed.), Quartly ART report for July 2013. Kampala Ministry of Health, Government of Uganda. Kampala.

Mpango, R. S., Kinyanda, E., Rukundo, G. Z., Levin, J., Gadow, K. D., \& Patel, V. (2017). Prevalence and correlates for ADHD and relation with social and academic functioning among children and adolescents with HIV/AIDS in Uganda. BMC psychiatry, 17(1), 336.

Mutumba, M., Musiime, V., Lepkwoski, J. M., Harper, G. W., Snow, R. C., Resnicow, K., \& Bauermeister, J. A. (2016). Examining the relationship between psychological distress and adherence to anti-retroviral therapy among Ugandan adolescents living with HIV. AIDS care, 28(7), 807-815.

Paramesparan, Y., Garvey, L. J., Ashby, J., Foster, C. J., Fidler, S., \& Winston, A. (2010). High Rates of Asymptomatic Neurocognitive Impairment in Vertically Acquired HIV-1-Infected Adolescents Surviving to Adulthood. JAIDS Journal of Acquired Immune Deficiency Syndromes, 55(1), 134-136.

Patel, V., Flisher, A. J., Hetrick, S., \& McGorry, P. (2007). Mental health of young people: a global public-health challenge. The Lancet, 369(9569), 1302-1313.

Uganda AIDS Commission. (2015). The Uganda National HIV and AIDS Strategic Plan 2015/2016 - 2019/2020. 
Wagner, G. J., Ngo, V., Glick, P., Obuku, E. A., Musisi, S., \& Akena, D. (2014).

INtegration of DEPression Treatment into HIV Care in Uganda (INDEPTH-

Uganda): study protocol for a randomized controlled trial. Trials, 15(1), 248.

White, G. M. (1982). The ethnographic study of cultural knowledge of "mental

disorder" Cultural conceptions of mental health and therapy (pp. 69-95):

Springer.

White, G. M., \& Marsella, A. J. (1982). Introduction: Cultural conceptions in mental health research and practice Cultural conceptions of mental health and therapy (pp. 3-38): Springer.

WHO. (2015). Treat all people living with HIV, offer antiretrovirals as additional prevention choice for people at "substantial" risk. [Press release]. Retrieved from http://www.who.int/mediacentre/news/releases/2015/hiv-treat-allrecommendation/en/ 
Table 1.

Socio-demographic characteristics of study respondents:

\begin{tabular}{|c|c|c|c|c|c|}
\hline \multicolumn{3}{|l|}{ Adolescents $=19$} & \multicolumn{3}{|c|}{ Caregivers of children 5-11years old= 19} \\
\hline \multicolumn{2}{|l|}{ Age in years } & $12-17$ & \multicolumn{2}{|l|}{ Age in years } & $28-69$ \\
\hline \multicolumn{2}{|l|}{ Median age } & 14 & \multicolumn{2}{|l|}{ Median age } & 40 \\
\hline \multirow[t]{2}{*}{ Gender of adolescent } & Female & $\begin{array}{l}11 \text { (7 } \\
\text { urban) }\end{array}$ & \multirow[t]{2}{*}{ Gender of caregiver } & Female & $\begin{array}{l}17 \\
\text { (urban) }\end{array}$ \\
\hline & Male & 8 (2 urban) & & Male & 2 (urban) \\
\hline \multirow[t]{6}{*}{ Primary caregiver to } & \multirow[t]{3}{*}{ Both parents } & \multirow[t]{3}{*}{6} & \multirow{4}{*}{$\begin{array}{l}\text { Relationship of } \\
\text { caregiver to child }\end{array}$} & Grandmother & 6 \\
\hline & & & & Father & 2 \\
\hline & & & & Mother & 8 \\
\hline & Mother only & 5 & & Paternal aunt & 2 \\
\hline & Grandmother & 5 & & Step mother & 1 \\
\hline & Other relative & 3 & & & \\
\hline \multirow[t]{3}{*}{ Level of education } & Secondary & 4 & \multirow[t]{3}{*}{ Level of education } & Secondary & 8 \\
\hline & Primary & 13 & & Primary & 9 \\
\hline & Dropped out & 2 & & Non-formal & 2 \\
\hline
\end{tabular}


Table 2

Overall view of mental disorders in HIV positive children and adolescents

\section{Overall view of mental disorders in HIV positive children and adolescents}

1. Knowledge and recognition of mental disorders

\begin{tabular}{|lll}
\hline Conduct & Caregiver & $\begin{array}{l}\text { Improper upbringing } \\
\text { Violence }\end{array}$ \\
\cline { 2 - 3 } & Adolescent & Social challenges \\
& & Mental problems \\
& Unhappiness \\
\hline Depression & Caregiver & Poverty \\
& & Bereavement \\
\cline { 2 - 3 } & Adolescents & Social challenges \\
\hline ADHD & Caregivers & No problem at all \\
\cline { 2 - 3 } & Adolescents & Not listening to parents \\
& & Mental illness \\
\hline Neurocognitive & Caregivers & Physical difficulty \\
& & Physical impact of HIV \\
\cline { 2 - 3 } & Adolescents & HIV related \\
& & Fear of death \\
& & HIV related stigma \\
& & Physical problem \\
& &
\end{tabular}

\begin{tabular}{|c|c|c|}
\hline \multirow[t]{2}{*}{ Conduct } & Caregiver & $\begin{array}{l}\text { Poor parenting } \\
\text { HIV } \\
\text { Violence of caregivers }\end{array}$ \\
\hline & Adolescents & $\begin{array}{l}\text { Poor parenting } \\
\text { Violence } \\
\text { Verbal abuse } \\
\text { Social environment }\end{array}$ \\
\hline \multirow[t]{2}{*}{ Depression } & Caregivers & $\begin{array}{l}\text { Daily negative life events } \\
\text { ART side effects } \\
\text { Lack of fulfilment of basic needs }\end{array}$ \\
\hline & Adolescents & $\begin{array}{l}\text { HIV } \\
\text { Poverty } \\
\text { Grief } \\
\text { Discrimination } \\
\text { Heavy workload }\end{array}$ \\
\hline \multirow[t]{2}{*}{ ADHD } & Caregivers & Neglect \\
\hline & Adolescents & Parental death \\
\hline \multirow[t]{2}{*}{ Neurocognitive } & Caregivers & ART \\
\hline & Adolescents & $\begin{array}{l}\text { HIV } \\
\text { Low intelligence } \\
\text { Non-adherence to ART }\end{array}$ \\
\hline \multicolumn{3}{|c|}{ 3. Source of knowledge for mental disorders } \\
\hline Caregivers & & $\begin{array}{l}\text { Experience of people living with similar difficulties } \\
\text { Observation of experiences } \\
\text { Responses from others } \\
\text { Treatment and outcomes }\end{array}$ \\
\hline Adolescents & & $\begin{array}{l}\text { Experience of household member with a mental } \\
\text { disorder } \\
\text { Experience of similar symptoms }\end{array}$ \\
\hline
\end{tabular}

